\title{
SUSTAINABLE ORIENTED INNOVATION IN THE HOTEL INDUSTRY OF MAZATLÁN, MÉXICO
}

\author{
*Ibarra J.P1., Velarde $\mathbf{M}^{2}$., Olmos $\mathrm{E}^{3}$ and Alvarado $\mathrm{A}^{4}$
}

\author{
${ }_{1}^{1}$ Department of Social Sciences and Humanities. Universidad de Occidente. Mazatlán, México \\ 2,3,4 Department of Economic and AdministrativeSciences. Universidad de Occidente. Mazatlán, México
}

DOI: http://dx.doi.org/10.24327/ijrsr.2017.0805.0300

\begin{tabular}{l} 
ARTICLE INFO \\
\hline Article History: \\
Received $17^{\text {th }}$ February, 2017 \\
Received in revised form $21^{\text {th }}$ \\
March, 2017 \\
Accepted $28^{\text {th }}$ April, 2017 \\
Published online $28^{\text {th }}$ May, 2017 \\
\hline
\end{tabular}

Key Words:

Sustainability, Innovation, Hospitality.

\begin{abstract}
The tourist industry has been an important factor for the development of communities and countries but its repercussions to the environment and to the cultural and social heritage can be harmful for destinations if there's not a clear strategy to counterpart them. Mazatlán as a tourist destination is now embracing sustainability as a long-term strategy to maintain its resources in the future. As part of this strategy the program "sustainable hotels" has come up involving the private and the official sector along with some NGO's; this program has been successful as many hotels are now innovating trying to get recognition as a sustainable business. This multiple case research with a QUAN-QUAL approach unfolds the insights of the innovation process for sustainability and its results in three hotels enrolled in the program,highlighting the most important factors needed to become a sustainable business in the hospitality sector.
\end{abstract}

Copyright (C) Ibarra J.P et al, 2017, this is an open-access article distributed under the terms of the Creative Commons Attribution License, which permits unrestricted use, distribution and reproduction in any medium, provided the original work is properly cited.

\section{INTRODUCTION}

Sustainability criteria and efforts to adopt its "good practices" have had a major impact on all types of industries, especially on tourism, on the way in which strategies are planned and formulated to achieve the objective of being environmentally responsible companies. Today it has long been known that social responsibility and the attitude towards sustainability are factors of great importance for companies in all branches of industry (Porter and Derry, 2012). This is the result of a general increase in awareness of these issues among the public, which subsequently it is reflected in the demand to companies to comply a new set of standards of business practice and accountability (Porter \& Derry, 2012).

This aspect of social responsibility, which implies the adoption of good environmental practices and accountability in the economic repercussions of the company's performance, has to do with the current trends of the global society in which is increasingly demandingthemto do business with respect and responsibility towards nature and society. These attitudes portrait a new social awareness of respect for the environment where consumers, mainly in developed economies, prefer to consume products and services where these good practices are performed and the environment is respected (Porter \& Kramer, 2006).
In this sense, the company has to make adaptations and changes in organizational structure, infrastructure and trained staff, to adapt to these needs of the current market for which it is necessary to adopt a strategy where innovation plays a preponderant role. Innovation is a concept that since its introduction by Schumpeter (1934) has focused on the introduction of new organizational forms, means of production and markets, has evolved in such a way that currently it seeks the introduction of themes such as sustainability (Etzkowitz \& Zhou, 2006). This responds, as it is stated before, to a social demand that shows a growing interest in environmental issues and social justice.

Tourism, as an economic activity, has not been oblivious to these demands, so innovation with a sustainable orientation has been adopted by a growing number of companies in this sector, especially hotels (Gardetti \& Torres, 2016) mostly seeking for voluntary certifications to become environmentally responsible companies. This is because the hotel industry, as a fundamental part of the tourism industry can contribute significantly to the deterioration of the ecological balance due to the amount of waste it produces and the amount of inputs it needs, so its proper management is of utmost importance for the environmental sustainability of tourist destinations (Jauhari, 2014).

This research work tries to determine how the hotel sector of Mazatlán, a tourist destination located in western Mexico, has 
adapted and innovated to the new requirements of the national and international tourist market that is looking for more and more sustainable tourism destinations and products $\left(\mathrm{CREST}^{1}\right.$, 2015). An analysis was carried out from a multiple case study using a mixed methodology where the results of this type of innovation in the hotel companies selected for the study are detailed, showing a highly positive trend in the subject of sustainability already conceived among entrepreneurs as an important strategy when it comes to doing business.

\section{The concept of innovation}

The term "innovation" was widely disseminated after Schumpeter developed a whole theory about this idea which he defined as "new ways of doing things, or [as] better, unique combinations of the factors of production" (1934, p. 84), being this activity the most important for any business in a competitive environment. According to the author the innovation can be given in five main areas:

- $\quad$ generation of new or improved product

- introduction of new production processes

- development of new sales markets

- development of new supply markets

- reorganization or restructuring of the company

For Drucker (2007), innovation is "the specific tool of entrepreneurs, the means by which they exploit change as an opportunity for a different business or a different service" (p. 17). In this sense, innovation plays a fundamental role for any company that wants to be competitive by offering alternatives that are perceived as novel to their consumers or customers (Roger, 1962).

New approaches as the "Oslo Innovation Handbook" of the European Community (2005) defines innovation as "the introduction of a new, or significantly improved product (good or service), a process, a new marketing method or a new organizational method, in the internal practices of the company, the organization of the place of work or the external relations". This implies a great variety of ways in which innovation can be presented in the company being the improvement a common element within the process. These improvements can be created in the same company or be obtained from other companies or organizations so it is not limited only to the strictly new, but to what is useful to increase the competitive possibilities of the company no matter where it comes from, such as proposed by Chesbrough (2003) in its "open innovation" model.

This idea of openness is not new, authors such as Cohen \& Levinthal (1990) already proposed to see innovation not only as an internal process but as a process of assimilation of knowledge or learning, where the codification of tacit and explicit knowledge in the capacity to absorb them makes innovation easier, so the practice of management of knowledge must be stimulated by the organization. This is particularly true in companies that decide to follow the route of sustainability and need a whole range of new knowledge that will transform the organization's performance.

In this sense, innovation is presented as a change in several dimensions that comprises the tangible and intangible

\footnotetext{
${ }^{1}$ Center for Responsible Trave
}

structures of the organization as Tidd, Bessant \& Pavitt (2008) points out in his "4Ps" of innovation:

- Product innovation-changes in the things (products/services) which an organization offers;

- Process innovation- changes in the ways in which they are created and delivered;

- Position innovation-changes in the context in which the products/services areintroduced;

- Paradigm innovation-changes in the underlying mental models which frame whatthe organization does (p. 10).

It is clear that, by changing paradigms, the organization would have to induce not only a change in its artifacts or tangible manifestations, but also in its shared values and assumptions (Schein, 2009); that is, it would have to make a cultural change that is generally needed for the adoption of a new way of doing business as is the case of a sustainable business model.

For researchers is not easy to understand and explain all the process of innovation, that's why authors such as Sundbo (1997) came out with proposal like this four phases model to facilitate its study and comprehension: 1. Idea generating, 2. Transformation into an innovation project, 3. Development, 4. Implementation, however, as the same author points out: "the innovation process is rarely smooth and linear but complex and unpredictable" (p. 452).

It is in this way that innovation is presented as a complicated, but at the same time inspiring and rewarding process, that promotes the development of skills and creativity of the members of an organization. In the case of sustainability and the cultural paradigm shift required, the innovative process must therefore be inclusive and participatory in all its stages by multiple participants, highlighting the importance of a proactive and comprehensive leadership eager to reach all the objectives of sustainability.

\section{Innovation for sustainability}

Sustainability has now become another parameter to measure the competitiveness of companies, due to a direct relationship between, for example, good environmental practices and the reduction of fixed costs of the company, also implying an increase of consumption of products and services offered by the company (Willard, 2002). This competitive advantage or eco-advantage as it is called by Esty \& Winston (2006) is directly related to a growth of the market of ecological, green or environmental friendly products.

Companies that innovate by adopting sustainable business models have higher incomes and are more attractive to investors (Eccles, loannou, \& Serafeim, 2012, Niţă \& Ştefea, 2014), this means that including sensitive economic, social and environmental issues the companies are ensuring their longterm permanence by minimizing the negative effects of their operation in the short term (Porter \& Kramer, 2006).

Sustainability should not only be seen as a corporate image improvement strategy, but as an essential element to improve business performance in all its aspects, as well as an improvement to the working environment and the relationships with other external stakeholders of great importance, such as government, the community and other companies in the sector 
(Lozano, 2015). Intangible factors such as employee satisfaction and commitment are increasingly considered by companies around the world, who also perceive sustainability as an opportunity to innovate and thus increase their competitiveness (MIT Sloan Management Review \& The Boston Consulting Group, 2011).

Innovation then becomes a fundamental element for achieving sustainability in addition to a high competitive level. This type of innovation for sustainability according to Hautamäki (2010) means "activities that are based on ethically, socially, economically, and environmentally sustainable principles" (p.11). This concept, continues, consists of five principles: sustainable development, participatory innovation, continuous innovation, global innovation, and innovative management. These principles arise from the need to create a participatory synergy, in all levels and areas of the organization, that can contribute to the achievement of products and services that minimize their impact on the environment while meeting the needs of their consumers, ends Hautamäki.

Another author as Little (2004), defined "sustainability-driven" innovation as "the creation of new market space, products and services or processes driven by social, environmental or sustainability issues" (p. 3). Sustainable innovation should not only be linked to the creation of specific products and services for a well-defined market, but also involves a much deeper change in the philosophy and daily business of companies, as Charter (2007) states:

Sustainable innovation is a process where sustainability considerations (environmental, social, financial) are integrated into company systems from idea generation through to research and development (R\&D) and commercialization. This applies to products, services and technologies, as well as new business and organization models (p. 9)

Sustainable innovation, also called eco-innovation in the European Union, must therefore focus on "just creating new technologies but also in creating new services and introducing organizational changes are just as important" (EIO \& $\mathrm{CfSD}^{2}$, 2013) this implies then that "eco-innovationis about creating business models that are both competitive and respect the environment by reducing resource intensity of products and services" (p. 8).

This creation of sustainable business models has spread in practically all sectors of the economy, and as a consequence, every day more companies are seen following this philosophy, including, of course, the tourism and hotel industry.

\section{Sustainable innovation in hospitality}

The hotel industry and tourism in general have been a little slower to make decisions regarding the care of the environment because there was a wide consent that the negative effects that can cause on it are not so important nor so visible. This scrutiny on the negative effects and degradation, or even destruction, of the environment began in other types of industries such as chemicals and oil companies, however, since 1992 the trend of tourism and hotels in regard of sustainability has been focusing on concerns about the environment, the use of technology and the proper management of energy (Kalisch, 2002).

According to Doody (2010) "the concept of environmental sustainability has become a very serious and deep issue within the hospitality arena in the last decade. This is mainly due to the rapid pace at which customer needs and expectations are changing." It is from this new type of thinking of the user of tourism services that has brought a transformation to a greater or lesser extent of all organizations related to the activity.

Even so, sustainability still more a public relations issue (Wheeller, 1993) an obligation for many entrepreneurs that only try to fulfill the minimum requirements asked for the authority, basically because there's no an immediate return of the investment required (Swarbrooke, 1999). The necessary evolution to sustainability is not something that the tourist industry can avoid that easily because the enormous legacy of negative issues in the social, ecological and cultural aspects of destinations that can lead to their decline or disappearance at any given time (Butler, 1980). The responsibility of the hotels, as a major participant in the tourist activity, in this events can't be ignored (Sloan, Legrand \& Chen 2004), and a call for action is needed if tourist destinations want to preserve their natural and cultural resources through a more sustainable policies and practices (Berno\& Bricker 2001).

This scenery has led to the spread of sustainable culture in the hotel industrythat has been strengthened by initiatives such as the Green Hotels Association, Green Hotelier or Bio Hotels that focus on reducing energy use, water and solid waste production; their programs have been a positive influence in the change of managerial and employee attitudes in the industry that is now in a turning point to a more sustainable practice.Theinsertion of sustainability in any organization can bring great benefits in terms of the reduction of costs and therefore the increase in profits asEsty \& Winston (2006), Willard (2002), Eccles, loannou, \& Serafeim (2012), and Haanaes, Jurgens\& Subramanian (2013) state; however, the path to achieve this it's not easy, it will demand a lot of effort and it is clear that will require a great deal of innovations throughout all the organization(Gardetti \& Torres, 2016). Itshould be emphasized also, that sustainable innovation cannot be an isolated phenomenon within the boundaries of companies, but must take into account other dimensions and stakeholders.

Nowadays it is accepted that the hotel industry as a fundamental part of tourism activity can contribute significantly to the deterioration of the ecological balance due to the amount of waste it produces and the amount of inputs it needs, so its proper management is vital for the environmental sustainability of the tourist destinations(Jauhari, 2014). The tourist and the society in general has undergone transformations that tend to generate a more active awareness and participation in the conservation of the environment, therefore they have become more demanding in the creation and fulfillment of norms and regulations that protect it. As a consequence, the tourism industry, in general, has had to adopt strategies that allow it to meet that demand, and also make it more competitive in the process, as they are submerged in a more diverse market that is looking for pristine and more 
environmentally friendly and ecologically balanced places (CREST, 2013).

As a result of the above, sustainable innovation has become an important strategy for competitiveness in this sector not only for hotels, but also for the tourist destinations. As Hjalager (1997, 2002 quoted by Mattson, Sundbo\& Fussing-Jensen, 2005) states in studying innovation in tourism "innovation policies should emphasize sustainability and initiatives from other sectors" (p.359). This implies the participation of stakeholders who can contribute directly or indirectly in creating and shaping innovations that can lead the tourist destination to a sustainable development path. Along with that,sustainability is a learning opportunity for the organization, because no change or innovation in this matter will be reach if their members don't change their mindset about it (Brazdauskas, \&Gaigalaite, 2015) and this will bring, most of the times,more committed and motivated employees (Lozano, 2015).

As a conclusion, it can be state that sustainable oriented innovation must be seen as an opportunity to do more business in a greener market, cutting costs and being more competitive, fulfill the demands of stakeholders related to sustainability and also have a better inner environment. These are some of the reasons why hotels and destinations are now more aware and are working in the matter, Mazatlán Mexico, among them.

\section{Mazatlán a tourist destination getting in the path ofsustainability}

Mazatlán, a tourist destination located in the Northwest of Mexico state of Sinaloa, currently occupies the sixth place in the country's reception of tourists and it counts with 9399 hotel rooms (SECTUR 2017), those numbers are now increasingly growingdue to the opening of the new Highway MazatlánDurango that facilitates the arrival of tourists from the east of the country. Given the increasing arrival of tourists the local hotel industry is facing the demand of official (the government) and unofficial actors (civil society) to formulate and implement a strategy for environmental care and sustainability of the tourist destination.

In this scenario, some hotel entrepreneurs in Mazatlán, authorities and the community in general have begun to pay attention to the importance of including sustainable strategies to make the destination more competitive and responsible with the environment.

Mazatlán has until today three officially certified hotels in environmental matters, through a government office PROFEPA $^{3}$ (Federal Attorney for Environmental Protection), these hotels: Playa Mazatlán and Pueblo Bonito, and Torres Mazatlán are only a part of the 85 that correspond to those that are classified with 3,4 and 5 stars that meet international standards (SECTUR ${ }^{4}, 2012$ ). This leaves a lot of room for the implementation of this new type of business model within a local tourism industry that has mostly been inclined to the mass tourism without considering the sustainability of the destination.
That is why in 2014, after reach a consensus,agencies such as the State Tourism Office, Sinaloa Economic Development Council (CODESIN), the Mazatlán Hotel Association, the NGO's CONSELVA Coasts and Communities and the International Community Foundation (ICF) the program "Sustainable Hotels of Mazatlán" was formulated. Thisprogram promotes the implementation of "Good Environmental Practices and Environmental Management Systems" in hotels that focus on optimizing the use of natural and material resources in the daily operation of the hotel sector, which will lead to a considerable reduction in the consumption of resources natural resources, as well as the generation of solid waste and waste water After the approval of this program in 2015, 15 hotels initially were part of it but only 12 remained as the program advanced, these hotels are: El Cid Resorts, Marina El Cid, Royal Villas, Don Pelayo, Torres Mazatlán, Playa Mazatlán, Misión Mazatlán, Las Flores, Ramada, Vista Mar, Luna Palace, Océano Palace. All the hotels follow the same methodological guide to reach sustainability including numerous innovations and changes in all their areas and/or departments.

This methodological approach to reach sustainability is on the basis of the concept of the "open innovation" process proposed by Chesbrough (2003), it is also a process of learning from the experiences of other companies in the field (Cohen \& Levinthal,1990), using both the tacit an explicit knowledge in order to fulfill all the objectives set by the program. This means that the hotel had to formulate a strategic plan with wellestablished chronogram to reach the objectives in time. The program considered that, in one year, the hotel must be able to fulfill all the requirements needed to look for an official certification from the government's offices, or even any prestigious organization specialized in this subject at international level.

\section{METHODOLOGY}

Three hotels that are part of the sustainable hotel program were chosen as case studies: Ramada, Playa and Torres. A QUANQUAL mixed methodology approach was chosen to strengthen the validity of the results. In the first stage, a compliance guide was applied with a total of 122 items divided into five different departments of the hotel that are fundamental for its operation: housekeeping (29 items), food and beverage (16 items), laundry (13 items), maintenance (38 items) and management (26 items).

This compliance instrument contains, according to the program "Sustainable hotels of Mazatlán", all the aspects that were considered susceptible to be innovated in the company to achieve sustainability, including: processes, product and even paradigm, as it includes aspects that correspond to the usual behaviors derived from corporate values of the employees more than the obligations acquired. All of these elements of the innovation process required by the program has to do with the core of the sustainable thinking like the well-known three " $r$ ' $s$ ": reduce, recycle, reuse. The results of this instrument are divided in a positive or "yes" answer for a visible innovation, negative or "no" answer for a non-compliance of the innovation required or a "partial" compliance answer when the innovation is not fulfilled completely. 
In a second stage, we interviewed mid-level and high-level employees who were in charge of implement innovations and changes that are marked in the program, besides being responsible for being the promoters of shifting the current paradigm in the organization. The questions asked are related to the perception of sustainability and its relation to competitiveness, its integration with corporate strategies, openness to the creative participation of the members of the organization with innovative ideas and the change of paradigm in the organization.In the end, a labor of complementing and strengthening the data obtained from the quantitative compliance guide with the answers of the interview were made in order to provide a clearer image of the innovation process and its visible results in the studied hotels.

\section{RESULTS}

\section{Ramada Hotel}

With a level of compliance of $93 \%$, the hotel managed to exceed expectations in terms of its performance in the Sustainable Hotel program due to its recent incorporation to this new model of doing business. This effort began in 2014, and nowthe hotel is currently in the process of obtaining the certification of Environmental Quality in Tourism that grants the Mexican government through the Federal Attorney's Office for Environmental Protection (PROFEPA). This, in the words of its executives, demonstrates a high level of commitment for the achievement of sustainability since it is investing the time and money for it.

Table 1 Level of compliance for sustainability (guide)

\begin{tabular}{ccccc}
\hline Total Items & Yes & No & Partial & \%Total Compliance \\
\hline 122 & 110 & 5 & 7 & 93 \\
\hline
\end{tabular}

Breaking down this result by department it was found that the one of greater compliance was housekeeping (96.55\%) and maintenance was the one that score the lowest $(88.46 \%)$; the explanation to this result, according to the observed, is because maintenance requires strong investments to have automated equipment with low energy consumption, for example in the control of public areas lightning, as well as the difficulty of finding suppliers of ecological products. Housekeeping personnel on the other hand performs with great diligence what has been required for sustainability, implementing innovative procedures designed for this sole purpose.

Numerous innovations had to be implemented in order to be acknowledge as a sustainable hotel and they can be unfolded like this: 75 process innovations, 27 product innovations, and 8 usual behaviors changed as a part of the paradigm innovation.

As a result of the interviews to the employees the sustainability orientation of the hotel was confirmed, as the answers to specific questions about the integration of this new philosophy to the strategic plans and policies were widely positive, they claimed, for example, "that it becomes a habit", "new projects are coming" and "there still work to do but we're on the right path". About the sustainability oriented innovations and the competitiveness of the hotel, all of the interviewed employees agree that it is an important factor to increase it, they stated that "it distinguishes us from other hotels", "it is something that our costumers ask for". The question about the openness and participation of the employees in the process of strategic planning and diffusing of the new paradigm, the answers were similar in a way that they emphasize the importance of the consensus needed to achieve this goal; they state that "most of the ideas come from the personnel", "it has been a lot of participation", "everybody can express their ideas".As can be seen, the Ramada Hotel shows a strong commitment to the integration of sustainability in its organizational culture paradigm. For this, the hotel has implemented a series of actionsthat have allowed the staff to become aware of the issue, which has allowed it to adapt more easily to the requirements derived from this new strategy. It becomes clear then, that if there is a harmony and consensus in what is done, the results will be positive specially when it is about a change in the way the company runs and make business in an everyday basis.

\section{Playa Hotel}

The results of the compliance guide show $83 \%$ of Positive outcomeswhich is lower than that obtained by Ramada Hotel and highlighted that a major effort is required to achieve sustainability as the program requires.

Table 2 Level of compliance for sustainability (guide)

\begin{tabular}{ccccc}
\hline Total Items & Yes & No & Partial & \%Total Compliance \\
\hline 122 & 93 & 13 & 16 & $\mathbf{8 3}$ \\
\hline
\end{tabular}

The detailed results of each department show a remarkable difference between the efforts made for this purpose. In the management and food and beverages department is found the lower performance in the effort for sustainability, which implies a lack of communication with the leaders of the program and a poor team work, as it was corroborated in the interviews made. In contrast, the laundry and housekeeping department showed an outstanding compliance, which reaches levels of $100 \%$ and $89.66 \%$ respectively and which exemplifies this disparity in performance expected for a company that already has some experienced in this issue. Total of innovations in Playa Hotel are unfolded as follows: 65 in processes, 21 in the product and 7 usual behaviors.

Despite the effort of reaching sustainability there are clearly some opportunity areas that need to be considered in order to fulfillall the compromises that come along with a sustainable business model.According to the interviews, a partial explanation was found for the level of performance that some departments show regarding sustainability; the owner and the general manager have put all the responsibility of the issue in a single person: the head of maintenance. This has meant, that despite an interest in meeting client and market expectations regarding sustainability, the little direct involvement of top management has influenced the way the problem is perceived and understood in the organization.

As stated by the maintenance chief he is the main responsible for spreading the related issues and working with the other bosses to achieve the goal of being sustainable but this arrangement hasn't been completely effective because of the little involvement of all the executive staff. The hotel also has an external consultant who helps to have technical and practical information on what you want to achieve. This arrangement has been effective, but not on the parameters that would be expected from a company certified as "environmentally clean" by an official government office (PROFEPA). The managers in the interview say that they fully understand that these sustainable practices are "an advantage over competition", and 
serve to promote themselves as "a clean company", in contrast, the perception of some executives on the impact on finance is that these efforts are "very costly", despite the fact that in the long run it has been shown that sustainability can become a saving in companies' operating costs (Esty \& Winston 2006); otherexecutives perceive this as an "investment for improvement" which speaks of the fact that there is no uniform perception of the substance and impact of sustainability.

The hotel privileges the efficiency in the achievement of objectives related to sustainability and according to what manifested its leader of quality assurance, is something that is presented as a series of procedures to follow without deepening much in the background behind these. There is no specific training program that allows the change of attitudes in the employees regarding the subject, but it is simply a combination of rules and processes to follow.

Another important aspect is that sustainability if perceived as a process of quality improvement in all aspects of the organization, as said by its manager of human resources, improve "products, people and the hotel in general", which serves to gain the recognition of guests during their stay. On the other hand, this manager is aware that more diffusion and convincing among hotel employees on this topic is needed.

The overall perception of this hotel regarding the sustainability and innovation process is that, despite all the efforts in this issue there's still a lack of commitment of many of its employees for it. It becomes clear that they need more information and sensitization about the sustainability final purposes. The hotel is innovating but more as a competitive matter not as an ethic or moral issue, so it is clear the the innovation of the cultural paradigm is not complete yet.

\section{Torres Hotel}

According to the results showed in the observation and compliance guide, this hotel is close to fulfill all the requirements needed to successfully achieve sustainability reaching $90 \%$ of compliance with innovation requirements. The commitment of the executives and employees and a direct involvement of the leaders result in a positive outcome as it is described ahead.

Table 3 Level of compliance for sustainability (guide)

\begin{tabular}{ccccc}
\hline Total Items & Yes & No & Partial & \%Total Compliance \\
\hline 122 & 107 & 9 & 6 & 90 \\
\hline
\end{tabular}

The fact of doing a very close and collaborative work in the different departments of the hotel results in a very uniform performance in the levels of compliance, which shows a commitment of the leadership in achieving the objective of sustainability with strategies that promote the involvement from bosses and employees, that is corroborated more ahead with the interviews. With the ratings obtained, this hotel exemplifies the correct execution of a great number of good practices that allow it to fulfill, with the necessary requirements to obtain certifications and recognitions related to the care of the environment or the sustainability in general. This is the result of many innovations but more importantly is due to the shift of the paradigm culture. The new set of values is widely spread in the hotel employees who are involved in all the processes of sustainability.A total of 107 innovations implemented are break down as follows: 76 in processes, 22 in product, and 9 usual behaviors, these results show a great performance in this kind of innovation.

Regarding the interviews conducted, the results shown are easily related to the survey made, corroborating the trend toward a culture oriented towards sustainability in its values and shared assumptions. Interviewees indicate that the role of the manager has been very "important" since it "guides" them towards the objectives previously agreed upon.

Following the route of sustainability, according to the interviewees, has been an important factor to considerably improve the quality of processes, not only those directly linked to this purpose but in all types, increasing the efficiency throughout all the hotel operation. As for the strategies to disseminate the concepts and values of sustainability, the human resources manager mentioned that training is regularly conducted and awareness-raising talks are held on the subject, making it a very important issue in development of attitudes and habits in the people who becomes a member of the organization.

There is a clear awareness that the role of middle managers is to reinforce good environmental practices, especially in the new entrants trying to integrate the current organizational culture; the subjects interviewed mentioned that it is a task of "raising awareness" and "opening the mind" of employees towards sustainability. Expressions like "the manager involves the employees", "they are the executors of the routines and strategies", "there are meetings and brainstorming" showed that this company privileges the communication and free expression of ideas in the formulation of strategies and plans to achieve the goal sought.

The sustainability approach has been spread in all of the company strategies as they claimed that "It is in everything that is done", "there is more order now working with sustainability in mind", "is part of corporate policy at all levels". According with the general management, the pursuit of sustainability is something that is derived from the corporate policies of the hotel chain to which they belong, and is not limited to ecological aspects, but is aimed at all its social and/or economic benefits. This, according to the manager, is something that has already become a cultural practice where no other form of work is conceived other than the one that seeks to cause the least damage to its environment, seeking in a similar way a direct benefit to the community.

Finally, it can be state that the most important innovation for sustainability has been successfully implemented in this hotel: the paradigm innovation. The uniformity of performance and the answers of the interviewed subjects, portrait a clear image of commitment and engagement with the matter, leaving the sensation that they are on the right path to reach more certifications at international level.

\section{DISCUSSION}

The tourism industry as many others is in the process of recognizing and solving the problem of being unaware of the damage that has been done to the environment. The global warming, the inequality of the economic models and other factors are a wakeup call for corporations and entrepreneurs 
that now are in the process of changing and innovating as a good way to be more competitive and to reach more markets.Indeed, sustainability, from the point of view of business, does not mean doing everything for altruism or doing the right thing simply for ethical or moral reasons; companies with profitable sustainable strategies are successful because they integrate considerations regarding clean design and conservation of resources through production processes or service delivery, that have a logic and practical meaning and makes them very efficient (Esty \& Winston, 2006, Willard, 2002). Sustainability-driven innovation must ultimately be a wealth-building practice for the private and social sectors while eliminating negative impacts on ecosystems, human health and communities.

The tourist market, like any other type of market, is exposed to the ups and downs of the economy and social phenomena that at a given moment can benefit or impair its performance. Under this scenario generating or adopting innovative ideas that materialize in more efficient organizational forms, saving of inputs, more prepared staff, modern and attractive infrastructure for the visitor as well as a set of amenities that enrich the visit of tourists are indeed very important; but is not enough to be innovative, today most societies are concern over the future of the planet and they are pressuring governments and corporations to be more sustainable (Lozano, 2012, Ganescu 2012). There are multiple benefits of being more "green" in the hospitality industry, some of them are being a driving force in the creation of more jobs, reduce poverty, support the local economy, conservation of ecosystems and cultural heritage and so on $\left(\mathrm{UNWTO}^{5} \& \mathrm{UNEP}^{6}, 2012\right)$, those factors, among others, are an important motivation for many tourist destinations that are seeking to stay in the tourist market for a long term.

This new trend of sustainable business model was embraced by many of the hotels located in Mazatlán and the results are evident and satisfactory to the stakeholders (community, government, $\mathrm{ONG}^{\prime}$ s and entrepreneurs) so far; this is also common sense, taking into account that more than one third of the visitors in a global level are in favor of more green products and services in hospitality willing to pay more for them (UNWTO \& UNEP, 2012).

Sustainability is more than a business model, is a philosophy, a way of thinking, a set of values that will lead the life of a given company that embraces it. This new trend in business demands not only product innovation but paradigm innovation as well in order to change the usual behavior that are less accepted by the market, communities and the official sector.

As Marée (2011) states "in the hospitality industry innovation should nowadays also mean 'business model innovation', either on rethinking the way you produce your product, on redefining yourindustry or on changing the way revenue is generated", this come very clear for business like the ones in this study, they not only stablish a new policy or a set of rules and practices, they have to rethink the way they conceive their business model, in other words, they have to change the core not only the surface of the company.

\footnotetext{
${ }^{5}$ World Tourism Organization

${ }^{6}$ United Nations Environment Programme
}

\section{CONCLUSIONS}

Mazatlán is intending to be a more sustainable destination and this program of "Sustainable Hotels" has been well accepted by tourist entrepreneurs and the community in general. The results in this first stage of the program are promising, despite of the problems that some hotels as the Playa have to implement this new model in all its departments and in homogenizethe heterogenous set of ideas display by their executives regarding the sustainability and the innovations needed.

Leadership stands out as an important factor to implement this innovation strategy, being clear that some of its characteristics must be those that are oriented towards empathy, teamwork, a global vision of the problem of sustainability and above all it has to be proactive and creative to get things done without hurting people or nature.

Most of the interviewed people agreed that sustainability is increasing the quality of their product and it is making them more competitive. This is a good incentive not only to these hotels but to the others hotels in the area who are following this process very closely.

The most important conclusion of this research is that sustainable innovation will be more successful if there is a strong involvement of leaders and followers, along with a collaborative work and consensus of the organization's personnel. The new set of values needed by any company that embraces sustainability has to be a result of a training and awareness process involving all personnel. This training and awareness has to be continuous to reinforced these ideas just Ramada and Torres hotel are doing it with an outstanding performance. Playa hotel is partially doing it and need to improve in some areas.

Finally,this study shows sustainability as a trend that is here to stay and an increasing number of companies are changing and trying not to be left behind. As the markets are changing and the demand for sustainable products is increasing, innovation becomes an important tool to fulfill this.

\section{References}

Berno T. \& Bricker B. (2001). Sustainable tourism development: the long road from theory to practice. International Journal of Economic Development 3, 3, 2001, pp. 1-18.

Brazdauskas, M., \&Gaigalaite, L. (2015). Sustainable Hotels as Learning Organizations: Innovative Approaches towards Employee Training. Innovation, 1.

Butler, R. W. (1980). The concept of a tourism area cycle of evolution: Implications for the management of resources. Canadian Geographer, 24, 5-12.

Charter, M \& Clark, T, (2007). Sustainable Innovation.The Centre for Sustainable Design.UK.

Chesbrough, H. W. (2003). Open Innovation. The new imperative for creating and profiting from technology. Harvard Business School Press. Boston MA.

Cohen, W. M. \& Levinthal, D.A. (1990).Absorptive Capacity: A New Perspective on Learning and Innovation. Administrative Science Quarterly, Vol. 35, No. 1, Special 
Issue: Technology, Organizations, and Innovation. (Mar., 1990), pp. 128-152.

CREST, Center for Responsible Travel (2013). The Case for Responsible Travel: Trends \& Statistics 2015. CREST. Washington DC. USA. Retrieved from:

http://www.responsibletravel.org/docs/2013\%20Trends\%20\& $\% 20$ Statistics_Final.pdf

CREST, Center for Responsible Travel (2015). The Case for Responsible Travel: Trends \& Statistics 2015. CREST. Washington DC. USA. Retrieved from:

http://www.responsibletravel.org/resources/documents/2015\%2 0Trends $\% 20 \& \% 20$ Statistics_Final.pdf

Doody, H. (2010). What are the barriers to implementing environmental practices in the Irish hospitality industry? In Tourism and Hospitality Research in Ireland Conference (THRIC). Shannon College Ireland.

Drucker P. (2007). Innovation and Entrepreneurship. Elsevier, Butterworth-Heinemann, Burlington, Mass, USA, Classic Collection.

Eccles, R.G., loannou, 1., \& Serafeim, G. (2012). The lmpact of a Corporate Culture of Sustainability on Corporate Behavior and Performance, working paper 17950, National Bureau of Economic Research Working Paper Series, Cambridge, Massachusetts, March

EIO \& CfSD (2013).Eco-innovate! A guide to eco-innovation for SMEs and business coaches. Eco-Innovation Observatory. Funded by the European Commission, DG Environment, Brussel.

Esty D. C.,\& Winston A. S., (2006).Green to Gold. Yale University Press, New Haven and London, 2006.

Etzkowitz, H., \& Zhou, C. (2006). Triple helix twins: Innovation and sustainability. Science \& Public Policy (SPP), 33(1).

Ganescu, M. C. (2012). Corporate social responsibility, a strategy to create and consolidate sustainable businesses. Theoretical and Applied Economics, 11(11), 91.

Gardetti M. A. \& Torres A. L. (2016).Sustainability in Hospitality: How Innovative Hotels are Transforming the Industry. Greenleaf Publishing Limited, UK.

Haanaes K., M. D., Jurgens J. \& Subramanian R. (2013) Making Sustainability Profitable. Harvard Business Review Magazine March (2013) 110-114.

Hautamäki, A. (2010). Sustainable innovation. A New Age of Innovation and Finland's Innovation Policy. Sitra (The Finnish Innovation Fund) Reports 87. Helsinki, Finland: Edita.

Jauhari, V. (Ed.). (2014). Managing sustainability in the Hospitality and Tourism Industry: Paradigms and Directions for the Future. Apple Academic Press.

Kalisch A. (2002). Corporate Futures: Social Responsibility in The Tourism Industry; Consultation on Good Practice. Tourism Concern, London.
Little, A. D. (2005). How Leading Companies are Using Sustainability-Driven Innovation to Win Tomorrow's Customers. Arthur D. Little, 2005.

Lozano, R. (2015). A holistic perspective on corporate sustainability drivers. Corporate Social Responsibility and Environmental Management, 22(1), 32-44.

Marée, G. (2011). Innovation Management in the Hospitality Industry: New Roads Towards Meaning and Corporate Culture. In Trends and Issues in Global Tourism 2011 (pp. 125-132). Springer Berlin Heidelberg.

Mattson,J., Sundbo, J. \& Fussing-Jensen,C (2005). Innovation Systems in Tourism: The Roles of Attractors and SceneTakers.Industry and Innovation, 12(3), 357-381.

MIT Sloan Management Review\& The Boston Consulting Group (2011).Sustainability: The 'Embracers' Seize Advantage. MIT Sloan Management Review and The Boston Consulting Group. Disponibleen: https://www.bcg.com/documents/file71538.pdf

Niţă Cornel G. \& Ştefea P. (2014).Cost control for business sustainability.Procedia - Social and Behavioral Sciences 124 (2014) 307 -311 ScienceDirect, Elsevier.

Porter, T. \& Derry, R. (2012). Sustainability and Business in a Complex World. Business and Society Review, 117: 3353.

Porter, M.E. \& Kramer M.R. (2006).Strategy and Society the Link Between Competitive Advantage and Corporate Social Responsibility. Harvard Business Review, December (2006) Pags. 72-87. Harvard Business School Publishing Corporation.

Schein, E. H., (2009). Organizational Culture and Leadership: A Dynamic View. $2^{\text {nd }}$ ed. Jossey-Bass, San Francisco.

Schumpeter J. A. (1934). The Theory of Economic Development. Harvard University Press. Cambridge Mass.

SECTUR, Secretaria de Turismo (2017). Resultados de la actividad hotelera Enero2017. SECTUR. Mexico. Retrievedfrom:

http://www.datatur.sectur.gob.mx/Documentos\%20Publicacion es/2017-MES_01_Publico.pdf

SECTUR, Secretaria de Turismo (2012). Compendio estadístico. Secretaría de Turismo. Gobierno del Estado de Sinaloa.

Sloan, P. Legrand, W., Chen, S. (2004).Factors influencing German hoteliers' attitudes toward environmental management.Advances in Hospitality and Leisure, Volume 1, p. 179-188.

Sundbo, J. (1997). Management of innovation in services. Service Industries Journal, 17(3), 432-455.

Swarbrooke, J. (1999)Sustainable Tourism Management, Wallingford: CABI.

United Nations Environment Programme and World Tourism Organization (2012), Tourism in the GreenEconomyBackground Report, UNWTO, Madrid. 
Wheeller B. (1993). Sustaining the ego. Journal of Sustainable Tourism 1 (2). 121-129.
Willard, B. (2002). The sustainability advantage: Seven business case benefits of a triple bottom line. Gabriola, B.C.: New Society Publisher

\section{How to cite this article:}

Ibarra J.P et al.2017, Sustainable Oriented Innovation In The Hotel Industry of Mazatlán, México. Int J Recent Sci Res. 8(5), pp.17183-17191.DOI: http://dx.doi.org/10.24327/ijrsr.2017.0805.0300 